Homocysteine and "Buerger's disease"

\section{Homocysteine and "Buerger's disease"}

\section{P A Courtney, P C Sharpe, R J E Lee}

Answers on p 504.

$\Lambda$ 42 year old woman presented with ischaemic left leg pain. There had been a right above knee amputation two years previously when Buerger's disease was diagnosed. However, on review of the arteriogram there was proximal disease in the superficial femoral artery suggesting atherosclerotic disease, and typical arteriographic features of Buerger's disease were absent. She had been a smoker of 30 cigarettes per day since age 16 years. At presentation two years after the right above knee amputation, the posterior tibial and dorsalis pedis pulses were absent in the left foot but there were no ischaemic ulcers in the toes. The following investigations were normal or negative: fasting blood sugar, lipid profile, C reactive protein, antinuclear antibody, rheumatoid factor, complement, anticentromere antibody, anti-Scl-70, anticardiolipin antibody, and thrombophilia screen. An echocardiogram was also normal.

Serum homocysteine was $117.9 \mu \mathrm{mol} / \mathrm{l}$ (5.5-13.6), serum methionine was 16 $\mu \mathrm{mol} / \mathrm{l}(22-32)$, serum folic acid was 3.5 $\mathrm{ng} / \mathrm{ml}(3.2-12.4)$, serum vitamin Bl2 was $225 \mathrm{pg} / \mathrm{ml}$ (158-1050), and serum vitamin B6 was $45 \mathrm{nmol} / \mathrm{l}(15-73)$.
Genetic testing revealed the patient was homozygous (TT) for the C677T polymorphism of methylenetetrahydrofolate (MTHFR).

\section{QUESTIONS}

(1) Which conditions should be excluded before making a diagnosis of Buerger's disease?

(2) What are the causes of a raised serum homocysteine?

(3) What is the appropriate treatment for this patient?

Postgrad Med J 2002;78:500

\section{Authors' affiliations}

P A Courtney, R J E Lee, Department of Medicine, Craigavon Area Hospital Portadown, Northern Ireland, UK P C Sharpe, Department of Clinical Biochemistry

Correspondence to: Dr Peter Sharpe, Department of Clinical Biochemistry, Craigavon Area Hospital, 68 Lurgan Road, Portadown, Northern Ireland BT63 5QQ, UK. psharpe@cahgt.n-i.nhs.uk

Submitted 29 January 2002

Accepted 25 March 2002 glucose $14.2 \mathrm{mmol} / \mathrm{l}$, and glycated haemoglobin was $10 \%$. Her serum protein was $50 \mathrm{~g} / \mathrm{l}$ and corrected serum calcium as well as lipid profile was normal. There was no evidence of ketonuria or microalbuminuria. A plain radiograph of the abdomen showed radio-opaque shadow at the level of right side of first lumbar vertebra. Contrast enhanced computed tomography of the abdomen was done and was abnormal (fig 1).

\section{QUESTIONS}

Answers on p 505.

A 26 year old woman presented with history of recurrent colicky abdominal pain since childhood. There was a history suggestive of steatorrhoea, polyuria, and polydipsia of eight years' duration. On general examination she had pulse rate of 80 beats/min, blood pressure 124/80 $\mathrm{mm} \mathrm{Hg}$, and there was no postural hypotension. Her height was $130 \mathrm{~cm}$, weight $28 \mathrm{~kg}$, body mass index $17 \mathrm{~kg} / \mathrm{m}^{2}$, waist circumference (W) 25 $\mathrm{cm}$, hip circumference $(\mathrm{H}) 27 \mathrm{~cm}$, and her $\mathrm{W} / \mathrm{H}$ ratio was 0.9 . There was pitting pedal oedema and loss of skinfold thickness. Systemic examinations including ophthalmoscopic examination were normal. Investigations revealed normal complete blood count, fasting blood glucose $11.1 \mathrm{mmol} / \mathrm{l}$, postprandial blood

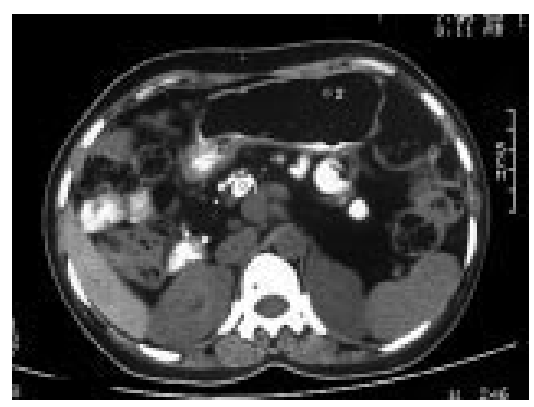

Figure 1 Contrast enhanced computed tomography of the abdomen.
(1) What is the diagnosis?

(2) What are the radiological features and radiological differential diagnosis?

(3) Why are these patients ketosis resistant?

Postgrad Med J 2002;78:500

Authors' affiliations

$S$ Bhoi, R Kumar, M Kumar, V Shukla, B Sharma, B B Gupta, Department of

Medicine, Dr Ram Manohar Lohia Hospital, New Delhi, India

Correspondence to: $\operatorname{Dr} B$ B Gupto D-II/M-2757, Netaii Nager, New Delhi 1 10023, India; dr_bbgupta@rediffmail.com

Submitted 18 January 2002

Accepted 26 March 2002 


\title{
Ischaemic foot: an unusual cause
}

\author{
M H Shiwani, S Bashker, A M M Basheer, P J Curley
}

Answers on p 505.

A 15 year old boy presented with a four month history of intermittent claudication of right calf at 500 yards, which gradually got worse and he subsequently developed numbness and discoloration of the right foot. He was a non-smoker, non-diabetic, and there was no history of cardiovascular, respiratory, or haematological disorders. There was no history of trauma, burns, or radiotherapy. His height was $1.88 \mathrm{~m}$ and weight $92.4 \mathrm{~kg}$ (body mass index $=26$ ). On examination he was normotensive with normal heart sounds and in sinus rhythm with no carotid bruit or aneurysm of the aorta or peripheral

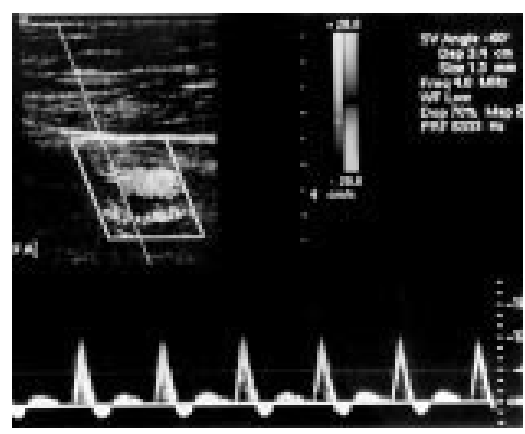

Figure 1 Duplex scan of his right femoral artery. arteries. He had a full complement of pulses on the left leg. On the right leg popliteal and foot pulses were not palpable. The right leg was cold below the mid-calf. There was no neurological deficit and no tissue loss. Ankle brachial pressure index of the right dorsalis pedis was 0.28 and left dorsalis pedis was 1 . Blood tests including full blood count, clotting time, $\mathrm{C}$ reactive protein, liver function test, thyroid function test, rheumatoid factor, autoimmune antibodies, and cholesterol were all within the normal range. The Duplex scans of his right leg arteries are shown in figs 1 and 2. A magnetic resonance angiogram (MRA) is shown in fig 3.

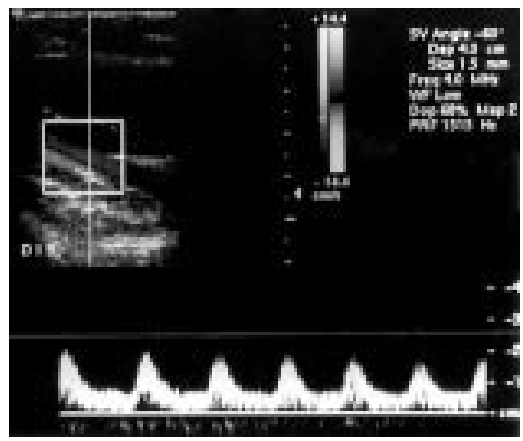

Figure 2 Duplex scan of his right popliteal artery.

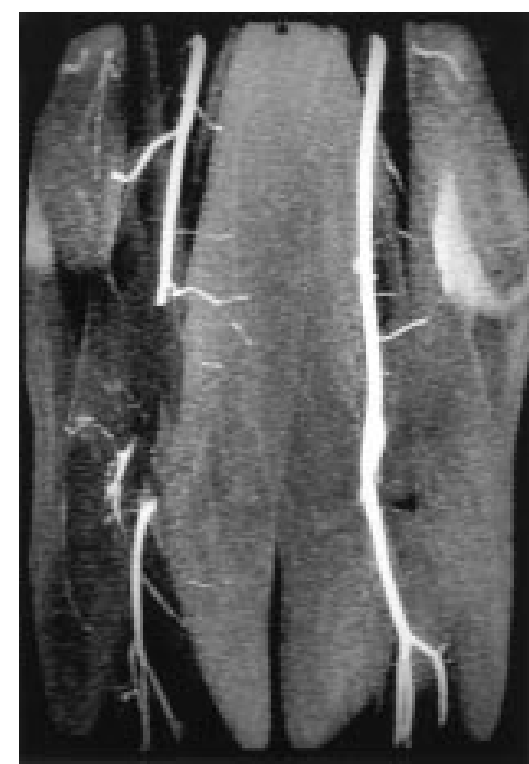

Figure 3 Magnetic resonance angiogram.

\section{QUESTIONS}

(1) What do the Duplex scans show?

(2) What does the MRA show?

(3) What are the causes of ischaemic foot?

Postgrad Med J 2002;78:501

\section{Authors' affiliations}

M H Shiwani, S Bashker, A M M Basheer, P J Curley, Department of Vascular Surgery, Pinderfield and Pontefract NHS Trust Hospitals, West Yorkshire, UK

Correspondence to: Mr M H Shiwani, Barnsley District General Hospital, Gawber Road, Barnsley S75 2EP, UK

Submitted 30 October 2000

Accepted 3 April 2001

\section{Type IV Ehlers-Danlos syndrome: a surgical emergency}

\section{Z Soonawalla, F M Pope, M Puntis}

\section{Answers on $p 506$.}

A 35 year old man was admitted with abdominal pain, distension and vomiting for three days, and haematochezia for one day. He was known to have type IV Ehlers-Danlos syndrome, and this had previously caused an intracerebral bleed and spontaneous haemopericardium. He also had a past history of ulcerative colitis controlled by azathioprine. On examination, he was dehydrated, with a temperature of $38^{\circ} \mathrm{C}$ and pulse of 110 beats/min. The abdomen was distended and diffusely tender, but was not guarded. Blood tests revealed a low white cell count, with normal renal chemistry and coagulation profile. An erect chest radiograph was taken (fig 1), after which he underwent emergency laparotomy. A postoperative computed tomogram of the abdomen was ordered (fig 2).

The patient recovered from this operation and stopped bleeding into his retroperitoneum. Seventeen days later, he developed sudden abdominal pain from perforative peritonitis. Relaparotomy revealed a free perforation of the sigmoid colon. Bleeding that necessitated splenectomy and packing complicated the surgery. He was administered fresh frozen plasma, cryoprecipitate, trasylol, tranexamic acid, and vitamin $\mathrm{K}$ in an effort to correct the bleeding tendency. The abdominal packs were subsequently removed and the abdomen was closed. 


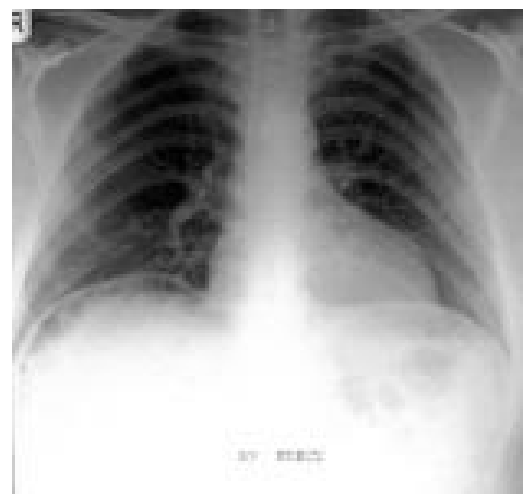

Figure 1 Chest radiograph.

The patient was weaned off the ventilator, but died nine days after his second laparotomy of an extensive myocardial infarction.

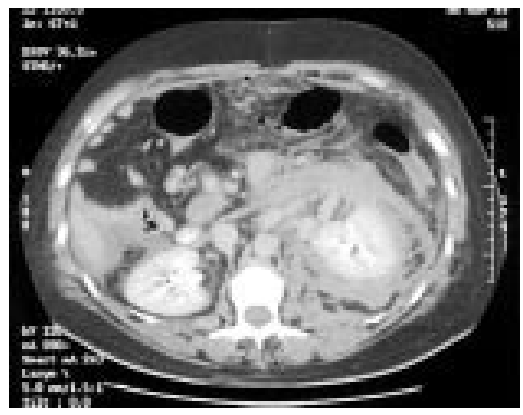

Figure 2 Abdominal computed tomogram.

Histology of the excised colon showed attenuation of the muscularis propria with no evidence of active colitis, confirming that the spontaneous perforation was due to Ehlers-Danlos syndrome and not the result of ulcerative colitis.

\section{QUESTIONS}

(1) What is seen on the chest radiograph?

(2) Comment on the history and computed tomogram.

Postgrad Med J 2002;78:501

\section{Authors' affiliations}

Z Soonawalla, M Puntis, Department of Surgery, University Hospital of Wales, Cardiff, UK

F M Pope, Department of Dermatology, West Middlesex University Hospital, Isleworth and Institute of Medical Genetics, University Hospital of Wales, Cardiff, UK

Correspondence to: Mr Zahir Soonawalla, Hepatobiliary and Liver Transplant Unit, Queen Elizabeth Hospital, Edgbaston, Birmingham B15 2TH, UK; soonawalla@aol.com

Submitted 13 August 2001

Accepted 7 January 2002

cystic, pituitary lesion (fig l). The laboratory work-up showed a mild elevation of basal prolactin levels, 1.05 IU/l; evaluation of pituitary reserve showed normal thyrotrophin, luteinising hormone, and follicle stimulating hormone responses after stimulation. The $\alpha$-subunit levels were $0.1 \mathrm{mIU} / \mathrm{ml}$. Mild bilateral superior constriction was found on Goldman visual field examination. There were no findings suggestive of sarcoidosis (normal chest radiography, normal serum angiotensin converting enzyme levels).

\section{QUESTIONS}

(1) What is the differential diagnosis for this patient?

(2) Which specific work-up should the follow up include?

Postgrad Med J 2002;78:502

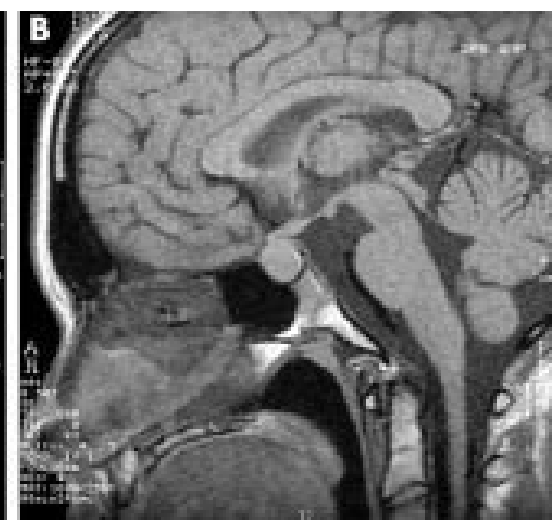

Figure 1 Magnetic resonance imaging at presentation (A, anterior view; $B$, sagittal view). A large pituitary space occupying lesion, with suprasellar extension, is evident.

\section{Authors' affiliations}

I Ilias, E Zapanti, G Philippou, 1st

Department of Endocrinology, "Alexandra"

University Hospital, Athens, Greece M Alevizaki, Endocrine Unit, Department of Clinical Therapeutics, University of Athens Medical School, "Alexandra" University Hospital, Athens, Greece

Correspondence to: Dr Maria Alevizaki, Department of Clinical Therapeutics, University of Athens Medical School, "Alexandra" Avenue, Athens GR-1 1528, Greece; mani@otenet.gr

Submitted 17 September 2001

Accepted 21 May 2002 University Hospital, 80 Vassilissis Sofias 


\section{An unusual complication of ulcerative colitis}

\section{H R Ferguson, R P Convery}

Answers on $\mathrm{p} 507$.

A

48 year old man presented with cough, purulent sputum production, wheeze, and reduced exercise capacity. He described rapid weight loss of $9 \mathrm{~kg}$ over six months, associated with night sweats. He denied chest pain or haemoptysis. He had a 30 pack year cigarette habit and previously worked as a glazier.

Ulcerative colitis had been diagnosed 25 years previously, with rapid disease progression despite sulphasalazine treatment. This resulted in a panproctocolectomy the next year with a postoperative period complicated by a subphrenic abscess and wound dehiscence. There was no recurrence of gastrointestinal symptoms.

On examination he was cachectic with finger clubbing. There was a low grade pyrexia and functioning ileostomy. Chest auscultation revealed scattered coarse rales.

The neutrophil count was $16.5 \times 10^{9} / \mathrm{l}$, the $\mathrm{C}$ reactive protein was $121 \mathrm{mg} / \mathrm{l}$, and the erythrocyte sedimentation rate was $70 \mathrm{~mm} /$ hour. IgE was $154 \mathrm{U} / \mathrm{l}$ (normal $<100)$, autoantibody screen was negative, and p-antineutrophil cytoplasmic antibody (ANCA) was borderline positive with MPO-ANCA titre 27 $\mathrm{EU} / \mathrm{ml}$.
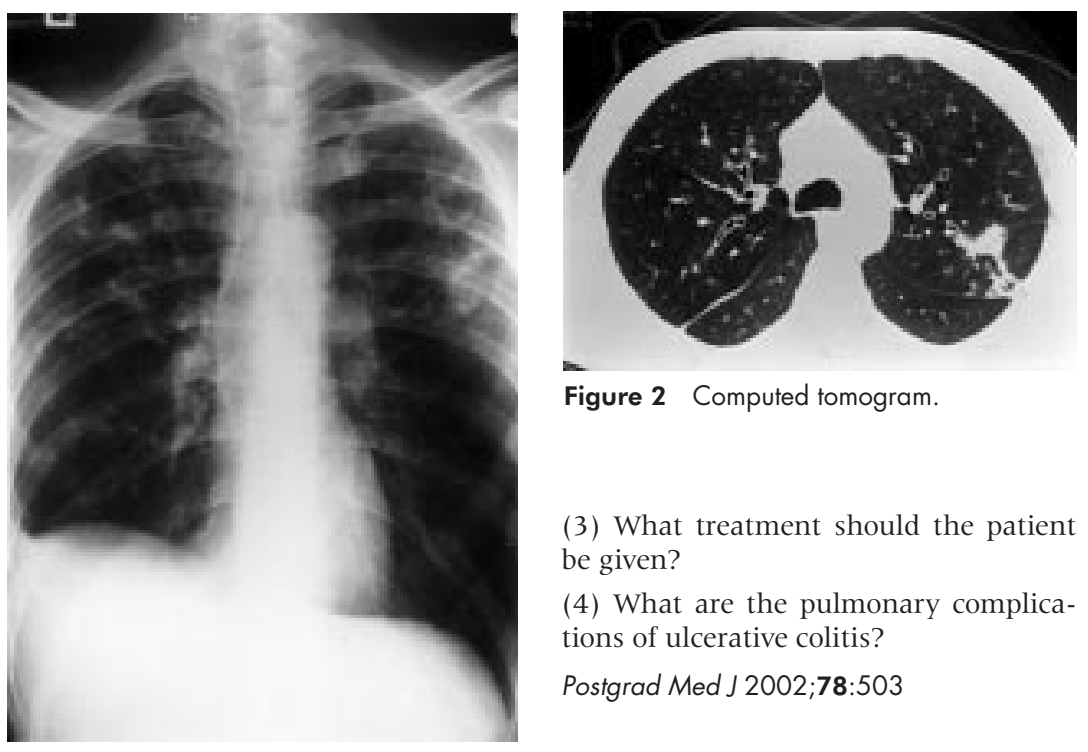

Figure 2 Computed tomogram.

(3) What treatment should the patient be given?

(4) What are the pulmonary complications of ulcerative colitis?

Postgrad Med J 2002;78:503

Figure 1 Chest radiograph.

\section{QUESTIONS}

(1) What do the chest radiograph (fig l) and computed tomogram of the upper thorax (fig 2) show?

(2) What is the likely diagnosis and what further investigations should be performed to confirm this?

\section{Authors' affiliations}

H R Ferguson, R P Convery, Department of

Medicine, Craigavon Area Hospital,

Correspondence to: Dr Ferguson; hrferguson@doctors.net.uk

Submitted 10 April 2002

Accepted 21 May 2002
Portadown, Northern Ireland, UK 